\title{
RELAÇÃO ENTRE CARACTERÍSTICAS FÍSICAS E O RENDIMENTO DE POLPA DE MARACUJÁ-AMARELO ${ }^{1}$
}

\author{
JACSON RONDINELLI DA SILVA NEGREIROS ${ }^{2}$, VIRGÍNIA DE SOUZA ÁLVARES ${ }^{3}$, CLAUDIO HORST BRUCKNER ${ }^{4}$ \\ MARCOS ANTÔNIO DELL'ORTO MORGADO ${ }^{5}$, COSME DAMIÃO CRUZ $^{6}$
}

RESUMO - O trabalho foi realizado na Universidade Federal de Viçosa (UFV), com o objetivo de avaliar a relação entre características do fruto de maracujazeiro e seus desdobramentos em efeitos diretos e indiretos para obtenção de maior rendimento de polpa e peso de frutos, norteando o melhoramento genético. As avaliações foram feitas no primeiro ano de produção (safrinha). Retirou-se uma amostra aleatória de 200 frutos em um ensaio com 42 progênies de meios-irmãos de maracujazeiro. Os caracteres avaliados foram: comprimento e diâmetro equatorial do fruto, peso do fruto, peso da casca e da polpa, espessura da casca, rendimento e relação comprimento/ diâmetro. Foram realizadas análises dos coeficientes de correlação de Pearson e análise de trilha. Verificaram-se correlações significativas entre os caracteres avaliados. O peso da polpa apresenta maior efeito direto em sentido favorável à seleção de peso de fruto. O diâmetro equatorial do fruto apresentou-se mais associado com o peso da polpa, em relação ao comprimento do fruto. A seleção dos frutos com maior diâmetro equatorial possibilita a obtenção de maracujás mais pesados e com maior rendimento. Não foi observada correlação entre a relação comprimento/diâmetro e rendimento de polpa.

Termos para indexação: Passiflora edulis, correlação, análise de trilha, qualidade de fruto.

\section{RELATIONS AMONG PHYSICAL FRUIT TRAITS AND PULP CONTENT IN YELLOW PASSION FRUIT}

\begin{abstract}
The work was carried out in the Federal University of Viçosa (UFV), with the aim to evaluate the relations among fruit traits of the yellow passion fruit and its direct and indirect effects on fruits weight and pulp content. The evaluations had been made in the first year yield with 200 randomly sampled fruits in an essay with 42 half-sib progenies. The data were submitted to Pearson's correlation and Path coefficient analysis. The evaluated traits were: length and equatorial diameter of the fruit, weight of the fruit, weight of the rind and the pulp, thickness of the rind, pulp weight/fruit weight ratio and length/diameter ratio. Significant correlations among the traits and yield were verified. The pulp weight had greater favorable direct effect for fruit weight selection. The equatorial diameter of the fruit was better associated with the length of the fruit than with pulp weight. The selection of fruits with greater equatorial diameter makes possible the attainment of passion fruits with higher pulp contents. Correlation between pulp content and length/diameter ratio (oval fruits) were not observed.
\end{abstract}

Index terms: Passiflora edulis, correlation, path analysis, fruit quality.

\section{INTRODUÇÃO}

A avaliação da produtividade é essencial no melhoramento genético de plantas. Entretanto, nas espécies frutíferas, além da produtividade, a qualidade dos frutos é também de grande importância, por determinar a aceitação do produto e ter grande influência no preço obtido. Essa qualidade do fruto é um termo amplo que engloba dimensões, coloração, sabor aroma, rendimento de polpa e outros atributos para os quais o consumidor é sensível (Albuquerque et al., 2002).
O conhecimento da correlação entre caracteres, nos programas de melhoramento genético, é importante quando se deseja fazer seleção simultânea de caracteres ou seleção indireta, principalmente quando o caráter de interesse apresenta baixa herdabilidade, problemas de medição ou de identificação. Neste caso, ao selecionar outro caráter de alta herdabilidade, de fácil medição, de fácil identificação e que apresenta alta correlação com o caráter desejado, o melhorista poderá obter progressos mais rápidos em relação ao uso de seleção direta (Goldenberg, 1968; Carvalho et al., 1999).

'(Trabalho 012-07). Recebido em : 03-01-2007. Aceito para publicação em: 13-07-2007. Trabalho executado com apoio financeiro da CAPES - Comissão de Aperfeiçoamento de Pessoal de Nível superior, CNPq -FAPEMIG.

${ }^{2}$ DS em Genética e Melhoramento, UFAC. Rio Branco - AC. CEP 69915-900. e-mail: jacsonrn@gmail.com.

${ }^{3}$ DS em Fitotecnia, UFV. Viçosa - MG. CEP 36571-000. e-mail: alvaresvs@yahoo.com.br.

${ }^{4}$ Departamento de Fitotecnia, UFV. Viçosa - MG, CEP 36570-000. e-mail: bruckner@ufv.br

${ }_{5}^{5}$ Graduando em Agronomia, UFV. Viçosa - MG, CEP 36570-000. e-mail: dell.orto@bol.com.br.

${ }^{6}$ Departamento de Biologia Geral, UFV. Viçosa - MG, CEP 36570-000. e-mail: cdcruz@ufv.br. 
Bruckner et al. (2002) ponderam que é necessário obter índices para realizar a seleção indireta de produtividade, uma vez que o maracujazeiro floresce e produz durante vários meses do ano, tornando trabalhosa a avaliação das plantas. Como a qualidade do fruto depende de várias características físicas, é importante determinar quais características têm maior efeito na qualidade dos frutos e que poderão ser empregadas na seleção de melhores frutos, facilitando as avaliações.

A principal causa de correlação genética é o pleiotropismo, embora a ligação gênica cause correlação transitória, especialmente em populações originadas de cruzamento entre linhagens divergentes (Falconer, 1987).

Apesar de importante, o coeficiente de correlação simples pode produzir equívocos a respeito da relação que há entre duas variáveis, podendo não ser uma medida real de causa e efeito. Assim, um alto ou baixo coeficiente de correlação entre duas variáveis pode ser o resultado do efeito que uma terceira variável ou um grupo de variáveis tem sobre essas duas variáveis, não dando a exata importância relativa dos efeitos diretos e indiretos destes fatores (Cruz et al., 2004).

Com o intuito de entender melhor as causas envolvidas nas associações entre caracteres, Wright (1921 e 1923) propôs metodologia de análise de trilha ("path analysis"), que desdobra as correlações estimadas em efeitos diretos e indiretos de caracteres sobre uma variável básica.

O sucesso da análise de trilha reside basicamente na formulação do relacionamento causa-efeito entre as variáveis (Schuster, 1996). Além disso, o desdobramento de correlações é dependente do conjunto de caracteres estudados, que normalmente é estabelecido a partir do conhecimento prévio de sua importância pelo pesquisador e de possíveis inter-relações expressas em diagramas de trilha (Cruz et al., 2004).

Os frutos de maracujazeiro-amarelo variam de arredondados a ovalados. Também há variações quanto ao tamanho, sabor, aroma, cor e quantidade de suco entre plantas formadas a partir de sementes de um mesmo fruto. Devido a esta variação na forma do fruto de maracujazeiro-amarelo, trabalhos têm sido desenvolvidos a fim de verificar a relação das dimensões com o rendimento de suco. Akamine e Girolami (1959) encontraram correlação entre a percentagem de suco tanto com o diâmetro como com o comprimento do fruto. Ferreira et al. (1975) verificaram a existência de correlação positiva entre comprimento e diâmetro do fruto, assim como maior correlação do diâmetro com o volume de suco. Albuquerque et al. (2002) encontraram correlação do peso da polpa com o comprimento e com o diâmetro do fruto. Já Akamine et al. (1974) recomendam, em circular de serviço de extensão, no Hawaii, a seleção de plantas com frutos ovais em detrimento das com frutos redondos, que produziriam frutos com $10 \%$ a menos de suco.

Este trabalho teve como objetivo analisar a relação entre características do fruto de maracujazeiro e seus desdobramentos em efeitos diretos e indiretos, visando a nortear o melhoramento genético na obtenção de frutos mais pesados e com maior rendimento de polpa.

\section{MATERIAL E MÉTODOS}

Foram coletados, aleatoriamente, 200 frutos de um ensaio com 42 progênies de meios- irmãos de maracujazeiro-amarelo conduzido na Universidade Federal de Viçosa (Negreiros et al., 2004). Os frutos foram provenientes de polinização natural. As avaliações foram efetuadas em março e abril de 2003, no primeiro ano de produção (safrinha). A colheita dos frutos destinados à análise foi efetuada no estádio "verde-amarelo" (Ceagesp, 2001).

Os caracteres avaliados foram: comprimento e diâmetro equatorial do fruto $(\mathrm{mm})$, peso do fruto $(\mathrm{g})$, peso da casca e da polpa (incluindo sementes) (g), espessura da casca (mm), rendimento de polpa (g) e relação comprimento/diâmetro.

As estimativas dos coeficientes de correlação foram calculadas pelo método de Pearson, descrito em Steel \& Torrie (1960) e, para análise de trilha, utilizou-se a metodologia descrita por Cruz et al. (2004). As análises foram realizadas com o auxílio do aplicativo computacional GENES - versão 2005 (Cruz, 2001).

$\mathrm{Na}$ estimação dos coeficientes de trilha, primeiramente, utilizou-se um diagrama em cadeia apresentando as relações causa-efeito, partindo-se da associação entre a variável básica peso do fruto, e seus componentes primários, peso da casca e peso da polpa com seus componentes secundários comprimento e diâmetro do fruto, espessura de casca e relação comprimento/ diâmetro. O segundo diagrama causal indicou a inter-relação da variável básica rendimento e seus componentes primários comprimento e diâmetro do fruto, espessura de casca.

\section{RESULTADOS E DISCUSSÃO}

Observa-se grande variação nas características dos frutos de maracujazeiro, principalmente comprimento e peso do fruto (Tabela 1). Verificaram-se correlações significativas entre a maioria das características do fruto de maracujazeiro (Tabela 2). O diâmetro equatorial do fruto apresentou maior correlação com o peso do fruto do que com o comprimento do fruto, embora a diferença tenha sido pequena (Tabela 2). Akamine e Girolami (1959) e Albuquerque et al. (2002) verificaram correlações entre percentagem de suco e peso da polpa, respectivamente, tanto com diâmetro quanto com comprimento do fruto. Ferreira et al. (1975) e Oliveira (1980) também verificaram maior correlação entre o diâmetro equatorial do fruto com o peso do fruto do que o comprimento com o peso do fruto em maracujazeiro- amarelo. Essas correlações são importantes, pois indicam que a seleção de plantas com frutos pesados poderá ser feita a partir da medição do diâmetro equatorial dos frutos, ainda no campo, sem necessidade de pesá-los, o que pode facilitar muito os trabalhos de seleção. No material genético estudado, a correlação entre rendimento de polpa e relação comprimento/diâmetro, entretanto, não foi significativa, o que não corrobora a hipótese de que frutos ovais tenham maior rendimento de polpa. Embora Akamine et al. (1974) recomendem a seleção de plantas com frutos de forma ovalada por, supostamente, apresentarem maior teor de suco, pelos dados aqui observados, o rendimento de polpa não tem relação com a forma redonda ou ovalada.

Considerando o primeiro diagrama causal, a análise de 
trilha evidenciou que o peso da casca e da polpa possuem alta correlação com a variável básica (peso do fruto), em que o peso da polpa possui maior efeito direto $(0,5732)$ do que o peso da casca $(0,5359)$ (Quadro 3). Esse alto efeito direto indica relação de causa e efeito, sendo o peso da polpa o principal determinante das alterações no peso do fruto. Além do mais, o peso da polpa é mais importante comercialmente que o peso da casca (Albuquerque, 2002). O coeficiente de determinação $\left(\mathrm{R}^{2}\right)$, em questão, foi igual à unidade, pois as variações da variável básica são totalmente explicadas por esse esquema causal (Tabela 3).

No peso da polpa, a variável diâmetro do fruto destacouse como mais associada, assumindo efeito direto de 0,7600 (Tabela 4) com mesmo sinal da correlação fenotípica e magnitude que corresponde a 1,62 vez o efeito residual. Esses dados indicam a possível seleção indireta da quantidade de polpa por meio da seleção baseada no diâmetro do fruto. Isso se justifica porque o diâmetro é mais facilmente medido, possibilitando avaliar maior quantidade de plantas ou progênies. O comprimento do fruto, além de apresentar efeito direto consideravelmente menor do que o diâmetro, apresentou alto efeito indireto via diâmetro do fruto.

Ferreira et al. (1975) encontraram correlações fenotípicas altas e positivas entre o peso do fruto e o comprimento e diâmetro dos frutos do maracujá-amarelo, com valores de correlação de 0,8069 e 0,8796 , respectivamente. Os autores também encontraram correlações fenotípicas altas e positivas entre o peso de polpa mais semente e o comprimento e diâmetro do fruto, com coeficientes de correlação de 0,6785 e 0,7671 , respectivamente, assim como maior correlação entre o diâmetro do fruto com o volume de suco, ou seja, frutos com maior diâmetro equatorial apresentam maior peso de fruto, maior quantidade de polpa e maior volume de suco. Os resultados dos autores estão de acordo com os deste trabalho, apontando que frutos com maior diâmetro equatorial apresentam maior peso de polpa (Quadro 4), indicando que há a tendência de os frutos de maior diâmetro equatorial terem maior volume de suco.

Quando se analisou o segundo diagrama causal, verificouse que o diâmetro do fruto apresentou maior efeito direto positivo sobre a variável básica rendimento de polpa, em relação ao comprimento do fruto (Tabela 5). A espessura da casca apresentou alto efeito direto, porém negativo $(-0,6993)$ sobre o rendimento, indicando que a espessura da casca tem alto efeito contrário sobre o rendimento de polpa. Portanto, o rendimento de polpa pode ser selecionado indiretamente com base na menor espessura da casca, visto ser o efeito negativo.

A seleção de frutos ovais, embora possa justificar-se em virtude de exigências de mercado, não deverá ser aplicada com o objetivo de aumentar o rendimento de polpa, em virtude de o efeito do diâmetro equatorial ser maior do que o comprimento no rendimento de polpa e na massa do fruto e da polpa.
TABELA 1 - Características físicas dos frutos de maracujazeiro-

\begin{tabular}{cccc}
\multicolumn{4}{c}{ amarelo. Viçosa - MG } \\
\hline Mariável & Mínimo & Máximo & Média + desvio-padrão \\
\hline Comprimento $(\mathrm{mm})$ & 48,300 & 117,780 & $79,939+13,307$ \\
Diâmetro $(\mathrm{mm})$ & 53,570 & 88,640 & $71,633+7,532$ \\
Peso fruto $(\mathrm{g})$ & 64,700 & 327,950 & $166,279+58,114$ \\
Peso polpa $(\mathrm{g})$ & 38,100 & 172,820 & $88,243+33,312$ \\
Peso casca $(\mathrm{g})$ & 26,600 & 155,130 & $78,036+31,145$ \\
Espessura de casca $(\mathrm{mm})$ & 1,830 & 15,600 & $7,209+2,076$ \\
Rendimento de polpa & 0,265 & 0,743 & $0,531+0,089$ \\
Rel comp/diâm & 0,902 & 1,329 & $1,115+0,070$ \\
\hline
\end{tabular}

TABELA 2 - Coeficientes de correlação fenotípico entre os componentes de produção em maracujazeiroamarelo. Viçosa - MG

\begin{tabular}{|c|c|c|c|c|c|c|c|}
\hline Varível & Diâmetro & Peso Fruto & Peso polpa & Peso casca & $\begin{array}{c}\text { Espessura } \\
\text { casca }\end{array}$ & $\begin{array}{l}\text { Rendimento } \\
\text { de polpa }\end{array}$ & $\begin{array}{c}\text { Relação } \\
\text { comp/diâm }\end{array}$ \\
\hline Comprimento & $0,7142^{\prime \prime \prime}$ & $0,8630^{\prime \prime \prime}$ & $0,7312^{\prime \prime}$ & $0,8282^{\prime \prime}$ & $0,1758^{3}$ & $-0,1255^{\text {ns }}$ & 0,7606 \\
\hline Diâmetro & & $0,8870^{\text {*** }}$ & $0,7760^{* *}$ & $0,8250 *$ & $0,3358^{* 8 *}$ & 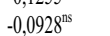 & $0,0962^{\mathrm{ns}}$ \\
\hline Peso fruto & & & $0,9083^{* *}$ & $0,8944^{* *}$ & $0,1814^{*}$ & $-0,0130^{\text {ns }}$ & $0,3977^{* *}$ \\
\hline Peso polpa & & & & $0,6253^{* *}$ & $-0,0787^{7 \mathrm{~s}}$ & $0,3854^{* *}$ & $0,3177^{* *}$ \\
\hline Peso casca & & & & & $0,4228^{* *}$ & $-0,4365^{* *}$ & $0,4023^{* *}$ \\
\hline Esp. casca & & & & & & $-0,6381^{* *}$ & $-0,0353^{\text {ns }}$ \\
\hline Rendimento de & & & & & & & $-0,0904^{\mathrm{ns}}$ \\
\hline
\end{tabular}

**, ": significativo a 1 e $5 \%$ de probabilidade pelo teste t, respectivamente. ns: não-significativo.

TABELA 3 - Efeitos diretos e indiretos dos componentes primários sobre o peso do fruto em maracujazeiroamarelo. Viçosa-MG

\begin{tabular}{lll}
\hline Característica & \multicolumn{1}{c}{ Efeito } & Estimativa \\
\hline Peso polpa & Direto sobre peso do fruto & 0,5732 \\
& $\begin{array}{l}\text { Indireto via peso de casca } \\
\text { Peso casca }\end{array}$ & 0,3351 \\
& Total & 0,9083 \\
& Direto sobre peso do fruto & 0,5359 \\
& Indireto via peso de polpa & 0,3584 \\
& Total & 0,8944 \\
\hline $\mathrm{R}^{2}$ & & 1,000 \\
Efeito residual & & 0,000 \\
\hline
\end{tabular}

TABELA 4 - Efeitos diretos e indiretos dos componentes secundários sobre os componentes primários do peso do fruto em maracujazeiro-amarelo. ViçosaMG

\begin{tabular}{lll}
\hline \multicolumn{1}{c}{ Descrição dos efeitos } & \multicolumn{2}{c}{ Componentes primários } \\
\cline { 2 - 3 } & Peso polpa & Peso casca \\
\hline Efeito direto de comprimento fruto & 0,1799 & 2,5697 \\
Efeito indireto via diâmetro fruto & 0,5428 & $-0,6789$ \\
Efeito indireto via espessura casca & $-0,0637$ & 0,0420 \\
Efeito indireto via relação comprimento/diâmetro & 0,0722 & $-1,1046$ \\
Total & 0,7312 & 0,8282 \\
\hline Efeito direto de diâmetro fruto & 0,7600 & $-0,9507$ \\
Efeito indireto via comprimento fruto & 0,1285 & 1,8352 \\
Efeito indireto via espessura casca & $-0,1216$ & 0,0802 \\
Efeito indireto via relação comprimento/diâmetro & 0,0091 & $-0,1398$ \\
Total & 0,7760 & 0,8250 \\
\hline Efeito direto de espessura casca & $-0,3622$ & 0,2389 \\
Efeito indireto via comprimento fruto & 0,0316 & 0,4518 \\
Efeito indireto via diâmetro fruto & 0,2552 & $-0,3192$ \\
Efeito indireto via relação comprimento/diâmetro & $-0,0034$ & 0,0513 \\
Total & $-0,0787$ & 0,4228 \\
\hline Efeito direto via relação comprimento/diâmetro & 0,095 & $-1,4522$ \\
Efeito indireto via comprimento fruto & 0,1368 & 1,9545 \\
Efeito indireto via diâmetro fruto & 0,0731 & $-0,0915$ \\
Efeito indireto via espessura casca & 0,0128 & $-0,0084$ \\
Total & 0,3177 & 0,4023 \\
\hline $\mathrm{R}^{2}$ & 0,7800 & 0,8608 \\
Efeito Residual & 0,4690 & 0,3731 \\
\hline
\end{tabular}

Rev. Bras. Frutic., Jaboticabal - SP, v. 29, n. 3, p. 546-549, Dezembro 2007 
TABELA 5 - Efeitos diretos e indiretos dos componentes primários sobre o rendimento do fruto em maracujazeiro-amarelo. Viçosa-MG

\begin{tabular}{llr}
\hline Característica & Efeito & Estimativa \\
\hline Comprimento do fruto & & \\
& direto sobre rendimento & $-0,2123$ \\
& indireto via diâmetro do fruto & 0,2097 \\
& indireto via espessura de casca & $-0,1229$ \\
& Total & $-0,1255$ \\
Diâmetro do fruto & & \\
& direto sobre rendimento & 0,2936 \\
& indireto via comprimento do fruto & $-0,1516$ \\
& indireto via espessura de casca & $-0,2348$ \\
Espessura de casca & Total & $-0,0927$ \\
& & $-0,6993$ \\
& direto sobre rendimento & $-0,0373$ \\
& indireto via comprimento do fruto & 0,0986 \\
& indireto via diâmetro do fruto & $-0,6380$ \\
\hline $\mathrm{R}^{2}$ & Total & 0,4456 \\
Efeito Residual & & 0,7445 \\
\hline
\end{tabular}

\section{CONCLUSÃO}

Com base nos resultados obtidos, pode-se concluir que houve correlações significativas entre os caracteres relacionados com a produção em maracujazeiro. Ganhos indiretos no peso do fruto podem ser obtidos via resposta correlacionada por seleção do diâmetro do fruto. A seleção dos frutos com maior diâmetro equatorial possibilita a obtenção de maracujás mais pesados e com maior rendimento de polpa, uma vez que o diâmetro tem maior efeito direto sobre o peso da polpa e rendimento. $\mathrm{O}$ rendimento da polpa também pode ser selecionado indiretamente, com base na menor espessura da casca. Não foi observada correlação entre relação comprimento/diâmetro (maior em frutos ovais) e rendimento de polpa.

\section{REFERÊNCIAS}

AKAMINE, E.K.; ARAGAKI, M.; BEAUMONT, J.H.; BOWERS, F.A.I.; HAMILTON, R.A.; NISHIDA, T; SHERMAN, G.D.; SHOJI, K.; STOREY, W.B.; MARTINEZ, AP.; YEE, W.Y.J.; ONSDORFF, T.; SHAN, T.N. Passion fruit culture in Hawaii. Hawaii, University of Hawaii, 1974. 35p. (Circular, 345)

AKAMINE, E.K.; GIROLAMI, G. Pollination and fruit set in the yellow passion fruit. Honolulu: University of Hawaii, 1959. 44p. (Technical bulletin, 39)

ALBUQUERQUE,A.S.; BRUCKNER, C.H.; CRUZ, C.D.; CASALI, V.W.D.; ARAÚJO, R. da C.; MOREIRA, A.E.; SOUZA, J.A. de. Possibilidade de seleção indireta para peso do fruto e rendimento em polpa em maracujá (Passiflora edulis Sims). In: CONGRESSO BRASILEIRO DE FRUTICULTURA, 17., 2002, Belém. Anais... Belém: Embrapa, 2002. CD-ROOM.

BRUCKNER, C.H.; MELETTI, L.M.;M.; OTONI, W.C.; ZERBINI JUNIOR, F.M. Maracujazeiro. In: BRUCKNER, C.H. Melhoramento de fruteiras tropicais. Viçosa: UFV, 2002. p.373-409.
CARVALHO, C.G.P. de; OLIVEIRA, V.R.; CRUZ, C.D.; CASALI, V.W.D. Análise de trilha sob multicolinearidade em pimentão. Pesquisa Agropecuária Brasileira, Brasília, v.34, n.4, p.603-613, 1999.

CEAGESP. Classificação do maracujá (Passiflora edulis Sims). Programa brasileiro para a melhoria dos padrões comerciais e embalagens de hortigranjeiros, São Paulo, 2001.

CRUZ, C.D. Programa GENES: versão Windows - Aplicativo Computacional em Genética e Estatística. Viçosa: Ed. UFV, 2001. $648 \mathrm{p}$.

CRUZ, C.D.; REGAZZI, A.J.; CARNEIRO, P.C.S. Modelos biométricos aplicados ao melhoramento genético. 3. ed. Viçosa: UFV, 2004.480p.

FALCONER, D.S. Introdução à genética quantitativa. Viçosa: UFV, 1987.279p

FERREIRA, F.R.; VALLINI,P.C.; RUGGIERO, C.; LAM-SANCHEZ, ALFREDO. Correlações fenotípicas entre diversas características do fruto do maracujá amarelo (Passiflora edulis flavicarpa). In: CONGRESSO BRASILEIRO DE FRUTICULTURA, 3., 1975, Rio de Janeiro. Anais... Rio de Janeiro: Universidade Federal Rural do Rio de Janeiro, 1975. p. 481-489.

GOLDENBERG, J.B. El empleo de la correlación en el mejoramiento genético de las plantas. Fitotecnia Latinoamericana, Costa Rica, v.5, n.2, p.1-8, 1968.

NEGREIROS, J.R.S.; BRUCKNER, C.H.; CRUZ, C.D.; SIQUEIRA, D.L.; PIMENTEL, L.D. Seleção de progênies de maracujazeiroamarelo vigorosas e resistentes a verrugose. Revista Brasileira de Fruticultura, Jaboticabal, v.26, n.2, p.272-275, 2004.

OLIVEIRA, J.C. de. Melhoramento genético de Pasiflora edulis f. flavicarpa Deg. Visando ao aumento de produtividade. 1980. 133f. Tese (Livre-Docência) - Faculdade de Ciências Agrárias e Veterinárias, Universidade Estadual Paulista, Jaboticabal, 1980.

SCHUSTER, I. Correlações, coeficientes de trilha, composição de gluteninas e qualidade do trigo para panificação. Viçosa: UFV, 1996.98p.

STEEL,R.G.D.; TORRIE, J.H. Principles and procedures of statistics. New York: McGraw-Hill, 1960.418p.

WRIGHT, S. Correlation and causation. Journal of Agricultural Research, Washington, v.20, p.557-585, 1921.

WRIGHT, S. The theory of path coefficients - a replay to Niles' criticism. Genetics, Austin, v.52, p.127-138, 1923. 